\title{
Targeting Hypoxia Signaling for Perioperative Organ Injury
}

\author{
Xiaoyi Yuan, PhD,* Jae W. Lee, MD,* Jessica L. Bowser, PhD,* Viola Neudecker, MD, $†$ \\ Srikanth Sridhar, MD,* and Holger K. Eltzschig, MD, PhD*
}

\begin{abstract}
Perioperative organ injury has a significant impact on surgical outcomes and presents a leading cause of death in the United States. Recent research has pointed out an important role of hypoxia signaling in the protection from organ injury, including for example myocardial infarction, acute respiratory distress syndrome, acute kidney, or gut injury. Hypoxia induces the stabilization of hypoxia-inducible factors (HIFs), thereby leading to the induction of HIF target genes, which facilitates adaptive responses to low oxygen. In this review, we focus on current therapeutic strategies targeting hypoxia signaling in various organ injury models and emphasize potential clinical approaches to integrate these findings into the care of surgical patients. Conceptually, there are 2 options to target the HIF pathway for organ protection. First, drugs became recently available that promote the stabilization of HIFs, most prominently via inhibition of prolyl hydroxylase. These compounds are currently trialed in patients, for example, for anemia treatment or prevention of ischemia and reperfusion injury. Second, HIF target genes (such as adenosine receptors) could be activated directly. We hope that some of these approaches may lead to novel pharmacologic strategies to prevent or treat organ injury in surgical patients. (Anesth Analg 2018;126:308-21)
\end{abstract}

$\mathrm{P}$ erioperative death is considered a leading cause of morbidity and mortality in the United States. ${ }^{1}$ The main cause of perioperative death includes acute organ injuries, for example, myocardial infarction (MI), acute respiratory distress syndrome (ARDS), acute kidney injury (AKI), and acute gut injury (AGI). While perioperative physicians acknowledge the detrimental impact of perioperative organ injury on surgical outcomes, opportunities to intervene are extremely limited. For example, clinical studies indicate that AKI has a highly detrimental impact on surgical outcomes, including cardiac and noncardiac surgery. ${ }^{2}$ In addition, even small increases of creatinine elevations below AKI definition are associated with a doubling of morbidity and prolonged hospital length of stay. ${ }^{2}$ In many instances, organ injury occurs at the interface of hypoxia and inflammation and is associated with the stabilization of hypoxia-inducible transcription factors (HIFs; Figures 1 and 2). HIFs belong to a group of transcription factors that mediate adaptation to hypoxia and are stabilized during a number of inflammatory conditions and diseases. ${ }^{4-6}$ Hypoxia and inflammation share an interdependent relationship because inflammation causes hypoxia and hypoxia causes inflammation. ${ }^{3}$ On 1 hand,

From the *Department of Anesthesiology, the University of Texas Health Science Center at Houston, McGovern Medical School, Houston, Texas; and †Department of Anesthesiology, Clinic of the University of Munich, Munich, Germany.

Accepted for publication May 16, 2017.

Funding: National Institute of Health Grants 2T32HL007747-21 to X.Y.; P50-CA098258 and DK056338 to J.L.B.; R01-DK097075, R01-HL098294, POI-HL114457, R01-DK082509, R01-HL109233, R01-DK109574, R01-HL119837 and R01-HL133900 to H.K.E.

The authors declare no conflicts of interest.

Reprints will not be available from the authors.

Address correspondence to Xiaoyi Yuan, PhD, Department of Anesthesiology, The University of Texas Health Science Center at Houston, McGovern Medical School, 6431 Fannin St, Houston, TX 77030. Address e-mail to Xiaoyi. Yuan@uth.tmc.edu.

Copyright (C 2017 International Anesthesia Research Society DOI: 10.1213 /ANE. 0000000000002288 many inflammatory diseases are characterized by hypoxia and stabilization of HIFs, as a result of alterations in tissue metabolism and increased oxygen demand from infiltrating immune cells. For instance, lung inflammation observed in acute lung injury (ALI) is associated with metabolic alterations leading to the stabilization of HIF- $1 \alpha .^{7}$ On the other hand, disease conditions that are primarily caused by lack of oxygen are characterized by inflammatory changes. For example, inflammatory responses are often observed in ischemia and reperfusion injury during solid organ transplantation and are the culprit for subsequent organ dysfunctions. ${ }^{5}$

As shown in Figure 1, hypoxia occurs during conditions of inflammation or infection with increased oxygen demand and decreased local oxygen supply leading to HIF stabilization. Decreased local oxygen supply can also be traced back to the compression of vasculature and vascular thrombosis, which further intensify tissue hypoxia. During inflammation, the infiltration of inflammatory cells, especially neutrophils, challenge the oxygen supply in the local microenvironment during tissue inflammation. Indeed, an elegant study by Campbell et $\mathrm{al}^{8}$ demonstrated the role of transmigrating neutrophils as oxygen scavengers in the mucosal microenvironment, leading to the stabilization of HIF. Besides "inflammatory hypoxia" and the great oxygen demand of inflammatory cells, processes after an acute infection can also result in the stabilization of HIF. Lipopolysaccharide (LPS), found in the outer membrane of Gram-negative bacteria, can elicit strong immune responses via toll-like receptor 4 signaling. ${ }^{9}$ Several studies indicated the ability of LPS or bacterial infection in the stabilization of HIF, suggesting an oxygen-independent way to activate HIF.10,11

Importantly, although hypoxia can be proinflammatory and lead to breakdown of mucosal and vascular barriers, the adaptive response to hypoxia, especially HIF stabilization, bears anti-inflammatory and tissue-protective aspects. Indeed, many studies show that pharmacological stabilization of HIF by HIF activators protects against tissue damage. ${ }^{4}$ Herein, we discuss how hypoxia signaling can be 


\section{Hypoxia and inflammation during perioperative organ injury}

Figure 1. Links between hypoxia and inflammation in perioperative organ injury. Left side of this figure shows examples of clinical conditions characterized by tissue hypoxia, which causes inflammation, including pulmonary edema, acute kidney injury, and ischemia/reperfusion injury. Inflammatory diseases that lead to tissue hypoxia are demonstrated in the right side of the figure, including acute lung injury, acute gut injury, and infection with pathogens. The interdependent relationship between inflammation and hypoxia renders hypoxia-inducible factor activation a desirable therapeutic intervention for perioperative organ injury. The figure is adapted from Eltzschig and Carmeliet. ${ }^{3}$ Copyright () 2011 Massachusetts Medical Society.
Figure 2. Regulation of hypoxia-inducible factor (HIF) protein levels under normoxic or hypoxic conditions. Under normoxic conditions, hydroxylation at 2 proline residues by prolyl hydroxylases (PHDs) promotes HIF- $\alpha$ association with von Hippel-Lindau (VHL) and leads to HIF- $\alpha$ destruction via the ubiquitin/proteasome pathway. In hypoxia, these processes are suppressed, allowing HIF- $\alpha$ subunits (both HIF- $1 \alpha$ and HIF- $2 \alpha$ ) to escape proteolysis, dimerize with HIF-1 $\beta$, translocate to the nucleus, and activate transcription via hypoxia-response element (HREs). HIF activation by PHD inhibitors, conservative oxygenation, ischemic preconditioning (IPC), and remote ischemic preconditioning (RIPC) can be potential therapeutic approaches for perioperative organ injury.
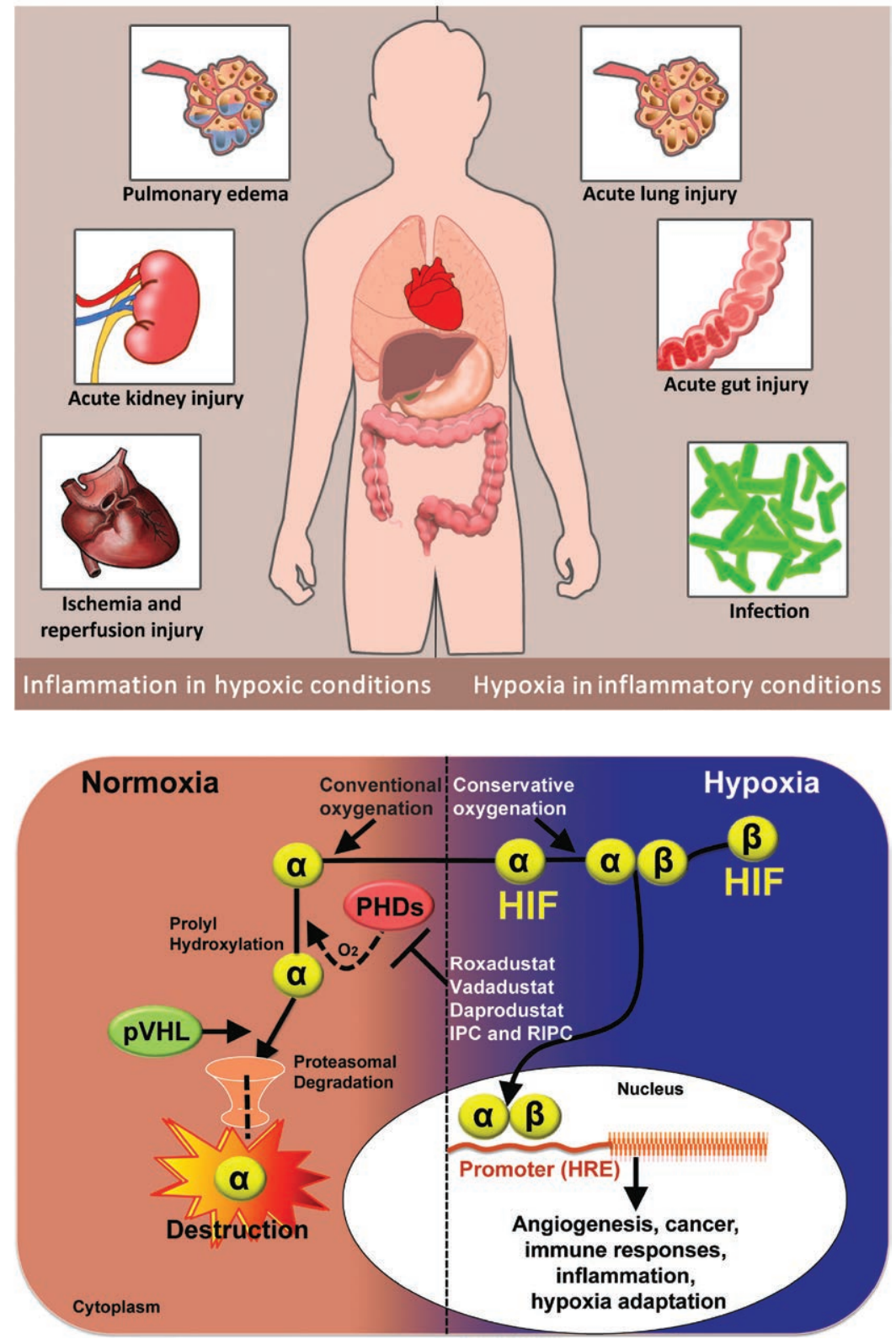

targeted therapeutically in patients as a potential treatment approach for the prevention or treatment of perioperative organ injury. This is particularly important due to the fact that many surgical procedures are performed electively and thereby provides the opportunity to introduce prophylactic treatment approaches to prevent perioperative organ injuries. Furthermore, future strategies may allow identification of patients at risk for a specific type of organ injury and facilitate the implementation of preventative measures. ${ }^{12}$

The oxygen-sensing pathway and detailed regulation of HIFs are illustrated in Figure 2. Briefly, HIFs are $\alpha \beta$ heterodimeric transcription factors that are essential to hypoxia adaptation, orchestrating transcriptional programs that regulate metabolism and maintain tissue homeostasis during hypoxic conditions. ${ }^{13,14}$ Under normal oxygen levels, HIF- $1 \alpha$ and HIF- $2 \alpha$ proteins are rapidly degraded in a process that involves hydroxylation by oxygen-sensing prolyl hydroxylases (PHDs) and binding of the von HippelLindau (VHL) gene product. ${ }^{15,16}$ This process promotes polyubiquitination and subsequent proteasomal degradation. Hypoxic conditions result in the functional inhibition of PHDs because PHDs require oxygen as cofactor, which stops the hydroxylation and in turn stabilizes HIFs. ${ }^{17}$ Upon stabilization, HIF- $1 \alpha$ forms a complex with the $\beta$-subunit and translocates into the nucleus to mediate transcriptional regulation by binding to hypoxia-responsive elements of target genes. ${ }^{18,19}$ Interestingly, it is estimated that over 5\% of all human genes are direct target genes of HIFs, which include genes that control cell metabolism, modulate inflammation, regulate apoptosis, and promote angiogenesis. ${ }^{20}$ Thus, targeting hypoxia signaling via modulation of HIFs may potentially have a profound impact on perioperative organ injury. Studying the HIF pathway for organ protection appears to be highly timely, as the 2016 Albert 
Lasker Basic Medical Research Award has honored 3 physician-scientists for their contribution to the discovery of the pathway by which mammalian cells sense and adapt to changes in oxygen availability.

During perioperative organ injury, the accompanying tissue damage results in the release of various mediators, for example, resolvins, maresins, and protectins from macrophages, ${ }^{21}$ as well as purines, particularly extracellular adenosine triphosphate (ATP) and adenosine diphosphate (ADP) from various cell types (Figure 3). This pathway is under the direct control of hypoxia signaling, as the enzymatic production of extracellular adenosine and some of the adenosine receptors are HIF-target genes. Specifically, extracellular adenosine is generated by the breakdown of ATP and ADP to adenosine. In detail, the conversion of ATP / ADP to AMP is performed by ectonucleoside triphosphate diphosphohydrolase-1 (CD39), which is induced during hypoxic or ischemic conditions. Studies implicate the transcription factor specificity protein 1 (Sp1) to be crucial in the induction of CD39 gene expression. ${ }^{22,33}$ The conversion of AMP to adenosine is catalyzed by ecto-5'-nucleotidase (CD73), which is a direct HIF target; CD73 expression is found elevated during hypoxia or ischemia in many organs and tissues. ${ }^{23}$ Similarly, the $\mathrm{A}_{2 \mathrm{~A}}$ and $\mathrm{A}_{2 \mathrm{~B}}$ adenosine receptors (A2AR and A2BR) are known HIF-target genes. ${ }^{34,35}$ As such, hypoxia signaling enhances the production and signaling effects of extracellular adenosine.

HIF activation represents a strong adaptive response to the change in oxygen levels. This response, when harnessed properly, can serve as a target to prevent perioperative organ injury. ${ }^{32}$ Although HIF activation can be achieved via hypoxia and bacterial infection, those conditions should always be avoided in perioperative patients. Enhancing HIF by HIF activators can potentially serve as a preoperative intervention to prevent organ injury. The mechanism by which HIF activators stabilize HIF is inhibition of PHDs. ${ }^{36,37}$ Since PHDs use oxygen and 2-oxoglutarate (2-OG) as cosubstrates, 2-OG analogues can act as competitive antagonists inhibiting the activity of PHDs. ${ }^{38,39}$ For instance, obstructive sleep apnea results in hypoxic conditions, which have been associated with insulin resistance and type 2 diabetes. ${ }^{40}$ PHD inhibitors, such as AKB-4924 increase HIF- $1 \alpha$ levels and enhance insulin secretion and glucose tolerance, implicating the possibility of HIF activators as a therapeutic approach for type 2 diabetes. ${ }^{41}$ Active clinical trials targeting hypoxia signaling are listed in the Table. In this review, we

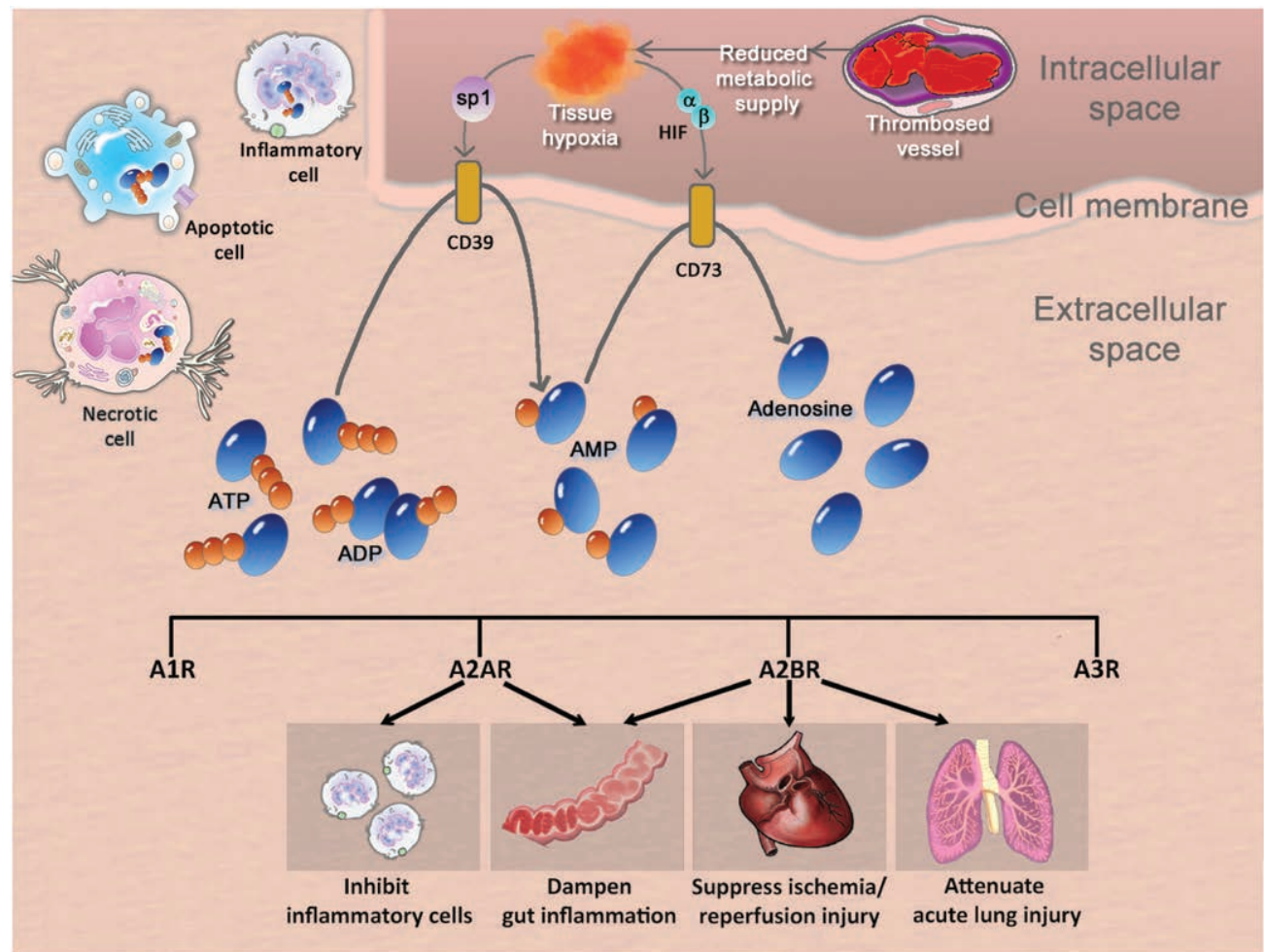

Figure 3. Control of extracellular adenosine generation and signaling during inflammation by hypoxia. During inflammatory conditions, multiple cell types release nucleotides, including activated inflammatory cells, apoptotic cells and necrotic cells, typically in the form of adenosine triphosphate (ATP) or adenosine diphosphate (ADP) from the intracellular compartment into the extracellular space. In acute organ injury, a decrease in oxygen supply (eg, due to vessel thrombosis) and significant increases in oxygen demand result in an imbalance in oxygen availability. Hypoxia causes Sp1-dependent induction of ectonucleoside triphosphate diphosphohydrolase 1 (CD39) ${ }^{22}$ and a hypoxia-inducible factor (HIF)-dependent induction of ecto-5'nucleotidase (CD73). ${ }^{23}$ Extracellular adenosine is generated primarily from the enzymatic conversion of ATP and ADP by CD39 and CD73. Extracellular adenosine can signal through 4 distinct adenosine receptors: adenosine $A_{1}$ receptor (A1R), adenosine $A_{2 A}$ receptor (A2AR), adenosine $A_{2 B}$ receptor (A2BR), and adenosine $A_{3}$ receptor (A3R). For example, activation of A2AR on inflammatory cells such as neutrophils ${ }^{24}$ or lymphocytes attenuates inflammation. ${ }^{25-27}$ As shown in other experimental studies, signaling events through A2BR facilitate tissue adaptation to hypoxia and attenuation of acute lung injury and ischemia/reperfusion injury. ${ }^{28,29}$ Activation of adenosine $\mathrm{A}_{2} \mathrm{AR}^{30}$ and $\mathrm{A} 2 \mathrm{BR}^{31}$ dampens intestinal inflammation and promotes epithelial integrity during intestinal inflammation. Current study suggested that adenosine receptor agonist has therapeutic potential to prevent and treat perioperative organ injury. Adapted from Eltzschig et al .32 Copyright (c) 2012 Massachusetts Medical Society. AMP indicates adenosine monophosphate. 


\begin{tabular}{|c|c|c|c|}
\hline Drug/Intervention & Study Population & Purpose of Study & ClinicalTrials.gov Number (Status) \\
\hline \multirow[t]{2}{*}{$\begin{array}{l}\text { Daprodustat/ } \\
\text { GSK1278863 } \\
\text { (GlaxoSmithKline) }\end{array}$} & $\begin{array}{l}\text { Dialysis subjects with anemia } \\
\text { associated with chronic kidney } \\
\text { disease (phase III) }\end{array}$ & $\begin{array}{l}\text { Study the safety and efficacy of } \\
\text { daprodustat compared to erythropoietin, } \\
\text { following a switch from erythropoietin- } \\
\text { stimulating agents }\end{array}$ & NCT02879305 (recruiting) \\
\hline & $\begin{array}{l}\text { Patients undergoing elective } \\
\text { descending thoracic aorta/ } \\
\text { thoracic aortic aneurysm (DTA/ } \\
\text { TAAA) repair (phase II) }\end{array}$ & $\begin{array}{l}\text { Test the hypothesis that GSK1278863 will } \\
\text { reduce neurologic, renal and/or cardiac } \\
\text { ischemia in subjects }\end{array}$ & NCT01920594 (completed) \\
\hline $\begin{array}{l}\text { Vadadustat/AKB-6548 } \\
\text { (Akebia Therapeutics) }\end{array}$ & $\begin{array}{l}\text { Subjects with incident dialysis- } \\
\text { dependent chronic kidney } \\
\text { disease (phase III) }\end{array}$ & $\begin{array}{l}\text { Evaluate the efficacy and safety of oral } \\
\text { vadadustat for the correction of anemia }\end{array}$ & NCT02865850 (recruiting) \\
\hline $\begin{array}{l}\text { Roxadustat/ FG-4592 } \\
\text { (FibroGen, San Francisco, } \\
\text { CA; Astellas Pharma, } \\
\text { Northbrook, IL; AstraZeneca, } \\
\text { Wilmington, DE) }\end{array}$ & $\begin{array}{l}\text { Chronic kidney disease patients } \\
\text { not on dialysis (phase III) }\end{array}$ & $\begin{array}{l}\text { Study the efficacy and safety of FG- } 4592 \\
\text { for the treatment of anemia }\end{array}$ & NCT01750190 (recruiting) \\
\hline $\begin{array}{l}\text { BAY 1067197/PARSiFAL } \\
\text { (Bayer) }\end{array}$ & $\begin{array}{l}\text { Patients with chronic systolic } \\
\text { heart failure (phase II) }\end{array}$ & $\begin{array}{l}\text { Investigate the safety, tolerability, } \\
\text { pharmacokinetics, and acute } \\
\text { cardiovascular responses of a 7-day oral } \\
\text { treatment with the partial adenosine } A_{1} \\
\text { receptor agonist BAY1067197 }\end{array}$ & NCT02040233 (completed) \\
\hline $\begin{array}{l}\text { Conservative } \\
\text { oxygenation }\end{array}$ & $\begin{array}{l}\text { Patients with acute respiratory } \\
\text { distress syndrome (phase III) }\end{array}$ & $\begin{array}{l}\text { Investigate the impact of liberal versus } \\
\text { conservative oxygenation on mortality }\end{array}$ & NCT02713451 (recruiting) \\
\hline
\end{tabular}

summarize past, current, and emerging therapeutic strategies targeting hypoxia signaling for 4 select conditions: MI, ARDS, AKI, and AGI.

\section{MYOCARDIAL INFARCTION}

MI is clinically characterized by abnormally high levels of plasma cardiac troponin concentration accompanied with at least 1 of the following criteria: ischemia, electrocardiogram abnormality, detection of intracoronary thrombus, or wall motion abnormality. ${ }^{42}$ The incidence of $\mathrm{MI}$ ranges from $1 \%$ to $3 \%$ in major noncardiac surgery and according to a multicenter international cohort study, MI results in about 5 times higher mortality rates (from $2.2 \%$ to $11.6 \%$ ). ${ }^{43-45}$ Prolonged ischemia leads to the death of cardiomyocytes and causes MI, which is further categorized into type 1 and type $2 \mathrm{MI}$. Type $1 \mathrm{MI}$ is usually caused by ischemia that results from acute coronary occlusion after the rupture of an atherosclerotic plaque. ${ }^{46}$ On the other hand, type $2 \mathrm{MI}$ is defined as ischemic imbalance from conditions unrelated to coronary artery diseases including anemia, arrhythmia, hypotension, and hypertension. ${ }^{42}$ Existing therapeutic interventions for MI include fibrinolytic therapy, $\beta$-blockers, antiplatelet/ anticoagulant agents, percutaneous coronary intervention (PCI), nitrates, and statins. For example, revascularization therapies, such as PCI with stents or balloon angioplasty or surgical revascularization by coronary artery bypass grafting, are very frequently utilized. Additionally, prevention of subsequent thrombotic events with the use of antiplatelet or anticoagulant medications is very common. Finally, supplemental oxygen therapy is frequently used as an initial treatment in patients experiencing $\mathrm{MI}$, but its routine use has become somewhat controversial. Although the effectiveness of traditional management of MI to reduce mortality has been proven, there are certain limitations. ${ }^{12}$ For instance, the accessibility of PCI-capable hospitals could be limited in rural areas while fibrinolytic therapy and antiplatelet/anticoagulant reagents could lead to potential detrimental side effects including stroke, which is commonly caused by brain hemorrhage. Most of the mentioned therapies for MI have the potential of introducing a new element of risk to patients, so it is essential to develop novel perioperative therapies to reduce the incidence of $\mathrm{MI}$ in a preventative manner and further decrease postoperative death related to MI.

Hypoxia that occurs with MI leads to the stabilization of $\mathrm{HIF}^{47}$ and several studies have suggested a cardioprotective role of $\mathrm{HIF},{ }^{28,48}$ which at least in part could be related to alterations in purinergic signaling events. ${ }^{49}$ Multiple studies have indicated the protective role of adenosine signaling in organ injury including the heart. ${ }^{50-54}$ The A2BR in particular has shown promising cardioprotective effects during myocardial ischemia/reperfusion injury. For instance, $a d o r a 2 b$ deletion in mice abolishes the protective effect of ischemic preconditioning (IPC) marked by increased infarct size after ischemia/reperfusion. ${ }^{55}$ Moreover, A2BR confers its protective activity via stabilization of circadian rhythm protein Period 2 (Per2), ${ }^{28}$ which supports the concept of light therapy for cardioprotection. ${ }^{48}$ Interestingly, cardiac Per2 levels fluctuate during the day with the highest levels of Per2 in the afternoon and early evening while lowest Per2 levels have been observed during the morning hours. Consistently, myocardial infarct size was largest during the morning hours while smallest in the evening, suggesting an inverse correlation between Per2 levels and infarct size. Despite the hypothetical nature, cardiac stabilization of Per2, such as via light therapy, might be considered as a novel therapy to reduce infarct size and attenuate ischemic/ reperfusion injury in patients.

Several studies have been conducted to demonstrate the safety and effectiveness of targeting HIF/adenosine signaling in the treatment of MI. Remote ischemic preconditioning (RIPC), which involves the repetitive ischemia/reperfusion to an arm or a leg before an ischemic condition in the myocardium, has shown significant myocardial protection. ${ }^{56}$ HIF-1 $\alpha$ is essential for RIPC-induced myocardial protection 
because gene silencing of HIF-1 $\alpha$ was shown to abolish the protective effect of RIPC. ${ }^{57}$ Furthermore, a recent study by Sarkar et a ${ }^{58}$ demonstrated a very interesting effect of HIF inhibitor to diminish the protection from IPC. Interestingly, this study showed mice with knockout of HIF- $1 \alpha$ or HIF$1 \beta$ in bone marrow and vascular endothelial cells to have complete absence of protection induced by IPC, whereas adenosine infusion restored the protection by IPC in these mice. Several pharmacological compounds are available, both promoting the stabilization of HIF via inhibition of oxygen sensors, such as PHDs, and further inducing the modulation of HIF-dependent genes. Although PHD inhibitors have not been tested in clinical trials for their effectiveness in the attenuation of MI, their safety has been proven in several clinical trials targeting anemia in chronic kidney injury (Table). In animal models, pretreatment with dimethyloxaloylglycine (DMOG), a 2-OG analogue, results in a significant reduction in infarct size after ischemic/reperfusion injury, which is accompanied by a considerable reduction of interleukin-8 when compared with sham-treated mice. ${ }^{59}$ Moreover, in vivo pretreatment with small interfering RNA silencing PHD2 attenuates murine myocardial infarct sizes, through modulation of A2BR signaling. ${ }^{60}$

Besides the pretreatment with HIF activators, eliciting the adenosine pathway can also serve as a novel therapeutic option to treat MI. For example, adenosine infusion has been proven to be effective during MI in clinical settings. ${ }^{61}$ Higher concentrations of adenosine correlated with reduced myocardial infarct sizes and the administration of adenosine within the first 3 hours after MI onset increased patient survival. ${ }^{62,63}$ Notably, the clinical effect of adenosine infusion is limited due to its short half-life. Consequently, there is great potential for adenosine receptor agonists as novel therapies for MI. Indeed, mice treated with BAY 60-6583, a specific agonist of A2BR, showed significant protection against MI marked by reduced infarct sizes in wildtype mice but not in mice with adora $2 b$ deletion..$^{29,55}$ Taken together, HIF activators, A2BR agonists, as well as light therapy represent potential therapeutic approaches in the attenuation of MI in patients.

\section{ACUTE RESPIRATORY DISTRESS SYNDROME}

ARDS is an inflammatory disorder of the lung creating significant impairment of oxygen exchange. It is defined by its clinical characteristics, including the following: (1) acute onset after pulmonary insult or manifestation, (2) radiologic imaging showing unexplained bilateral alveolar opacities, and (3) exclusion of heart failure or fluid overload as a cause of respiratory failure. ${ }^{64}$ The term "acute lung injury" has somewhat fallen out of favor in the description of this range of inflammatory lung pathology due to the variability in its practical use. The newly published Berlin definition of ARDS proposed subcategories based on the degree of hypoxemia (that would have previously encompassed the entity of "acute lung injury"): mild $\left(\mathrm{PaO}_{2} / \mathrm{FIO}_{2} \leq 300 \mathrm{~mm} \mathrm{Hg}\right)$, moderate $\left(\mathrm{PaO}_{2} / \mathrm{FIO}_{2} \leq 200 \mathrm{~mm} \mathrm{Hg}\right)$, and severe $\left(\mathrm{PaO}_{2} / \mathrm{FIO}_{2} \leq 100\right.$ $\mathrm{mm} \mathrm{Hg})^{64}$ The incidence of ARDS was reported to be $0.2 \%$ in patients undergoing general surgery and increased to $3 \%$ to $26 \%$ in patients with different risk factors such as higher risk surgeries, infection, and smoke inhalation. ${ }^{65,66}$ Contrary to the relative low incidence of ARDS in general surgery, the mortality of ARDS is high compared with other perioperative organ injuries, ranging from $27 \%$ to $40 \%{ }^{66,67}$ Both direct pulmonary injuries, such as pneumonia, aspiration, or pulmonary contusion, and indirect insults, such as sepsis, blood transfusion, shock, or pancreatitis, can result in ARDS. ${ }^{53,68-72}$ Premorbid conditions may be predictive of which patients may develop perioperative ARDS, with possible implicating factors such as emergency surgery, advanced age, preexisting renal failure, preexisting chronic or infective lung disease, and alcohol abuse. ${ }^{73}$ Typical symptoms of ARDS include severe pulmonary edema and uncontrolled lung inflammation, which results in impaired oxygen uptake and the need for ventilation. Treatment for ARDS is supportive in nature and can range from supplemental oxygen administration to mechanical ventilation, which on its own represents a potential cause of ALI leading to further lung damage. ${ }^{74}$ Management of mechanical ventilation in the setting of ARDS has been well described and is beyond the scope of this review; such strategies generally involve the use of lowtidal volume ventilation and close management of pressure parameters seen in ventilation of an injured lung. ${ }^{75}$ The same protective lung ventilation may be helpful in preventing ARDS as well, but there is continued debate on the effectiveness of such strategies. ${ }^{73}$ In extreme circumstances, extracorporeal membrane oxygenation may be utilized to allow for adequate oxygen delivery to the body and essentially allowing the lungs to rest for recovery. Several therapeutic reagents, such as methylprednisolone and omega-3 fatty acids, have been tested in clinical trials but proven ineffective in improving outcomes, ${ }^{76,77}$ which drives the search for novel therapeutic targets to reduce ARDS mortality.

Several factors contribute to the stabilization of pulmonary HIF during ALI. Besides "inflammatory hypoxia" and infection, which are explained in the introduction, other studies show that mechanical ventilation and concomitant cyclic mechanical stress can lead to the repression of the activity of succinate dehydrogenase. Subsequent elevations of pulmonary succinate levels during alveolar epithelial stretch can lead to inhibition of PHDs, as succinate is a known PHD inhibitor. ${ }^{7}$ Taken together, several pathways are likely to converge during conditions of ARDS resulting in the stabilization of HIFs. It may seem counterintuitive that an organ that is as highly oxygenated as the lungs can functionally experience hypoxia signaling. However, inflammatory and metabolic changes during ARDS account for the stabilization of HIFs, and HIF-dependent alterations in gene expression have been shown to dampen lung inflammation. Metabolic lung protection by HIFs includes the optimization of carbohydrate metabolism in pulmonary epithelial cells. ${ }^{7}$ In an in vivo murine model of ALI, HIF-1 $\alpha$ stabilization was observed under normoxic condition during ventilation-induced lung injury. Alterations in alveolar epithelial metabolism induced an HIF-dependent increase in glycolytic flux rates that provided a metabolic advantage in wild-type as opposed to mice with induced deletion of alveolar epithelial HIF-1 $\alpha .^{7}$ Moreover, alveolar epithelialspecific HIF-1 $\alpha$ deletion resulted in significant reduction in survival in a murine model of ALI. ${ }^{7}$ The same study also showed the HIF activator, DMOG as being beneficial while the HIF inhibitor, echinomycin resulted in a detrimental outcome of ALI. Together, these findings suggest that alveolar 
epithelial HIF stabilization functions to optimize carbohydrate metabolism during ARDS, and thereby dampens lung inflammation. Extensions of these findings indicate the possibility that inhaled HIF activators could in the future be used for ARDS treatment.

Other studies implicate alterations in purinergic signaling in mediating HIF-dependent lung protection. HIF signaling shifts the balance between proinflammatory ATP/ADP signaling to anti-inflammatory adenosine signaling via the induction of CD39 and CD73. ${ }^{78,79}$ Similarly, HIF-mediated increases in adenosine signaling, particularly through the A2BR, have been linked to improved alveolar fluid transport and attenuated lung inflammation. ${ }^{80,81}$ Interestingly, HIF-1 $\alpha$-dependent induction of netrin- 1 was observed in hypoxia-induced inflammation and netrin-1-dampened neutrophil transepithelial migration by engaging A2BR in both hypoxia-induced inflammation and LPS-induced lung injury. ${ }^{82,83}$ Additionally, A2BR was induced in both in vitro stretch studies and an in vivo ventilation-induced lung injury model while its induction was abolished after HIF inhibition or genetic deletion of HIF- $1 \alpha .^{34}$ Furthermore, aerosolized BAY 60-6583, an A2BR agonist, has been shown to attenuate pulmonary pathophysiology after ALI and traumahemorrhagic shock-induced lung injury. ${ }^{84,85}$ Collectively, HIF activators and adenosine receptor agonists appear to be promising therapeutic targets in the treatment of ARDS.

\section{OXYGENATION IN THE PERIOPERATIVE SETTING}

Hypoxia signaling, particularly stabilization of HIF protein or the induction of HIF target genes, have been implicated in the protection against acute organ injury, such as MI, ARDS, AKI, and AGI. A concern in this context has been that potentially higher levels of oxygen concentration (hyperoxia) could prevent the activation of these tissue-protective and anti-inflammatory pathways under the control of HIFs. Clinicians may have to exercise a careful balance as profound hypoxia in perioperative patients could lead to brain injury or detrimental injuries in other organ systems. Therefore, utilization of higher oxygen concentrations may frequently be imperative in order to avoid hypoxic injury to these organs ("Yin and Yang"; see Figure 4). For example, reviewing the clinical literature fails to elucidate an "ideal" concentration for oxygen delivery in the prevention and treatment of ARDS. Some reviews suggest a $\mathrm{PaO}_{2}$-driven model for supplemental oxygen delivery and indicate that $\mathrm{PaO}_{2}>100 \mathrm{~mm} \mathrm{Hg}$ may create "hyperoxia" conditions, with potential problems including atelectasis, systemic vascular constriction, proinflammatory states, and tissue damage caused by reactive oxygen species. ${ }^{86}$ Based on these findings, there has been a recent interest in perioperative studies to clinically define proper concentrations of oxygen.

Basic science studies have demonstrated the potential detrimental effect of hyperoxia on acute organ injury. For example, a landmark study from the laboratory of Dr Sitkovski demonstrated that "hyperoxygenation" could have a detrimental role in the development and exacerbation of ALI. ${ }^{87}$ In this study, mice receiving $100 \%$ oxygen showed significantly reduced survival rates in a bacterial infection-induced ALI model, when compared with mice receiving lower levels of oxygen. Mechanistically, this study suggested that higher levels of oxygen dampen the anti-inflammatory effects of

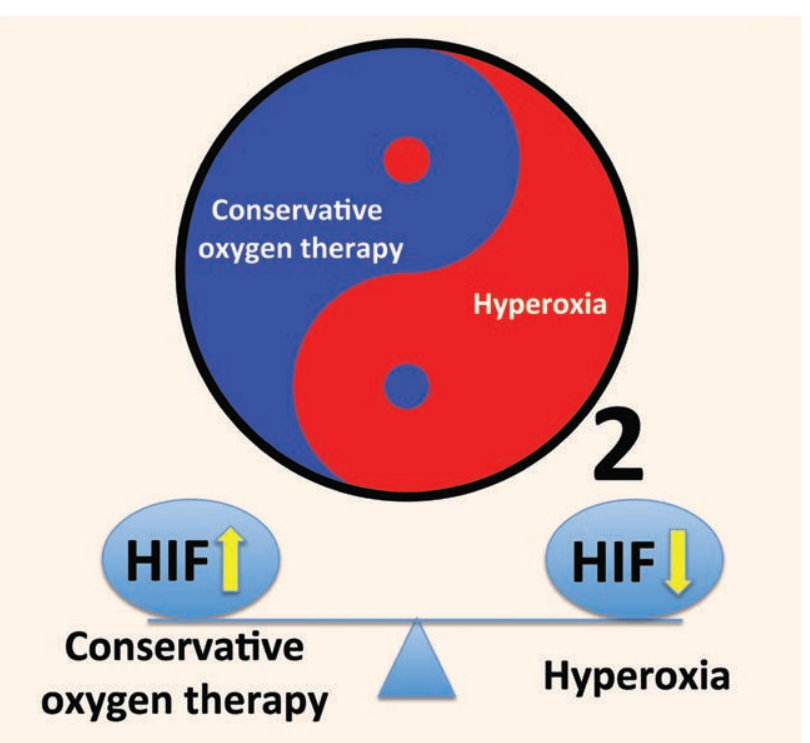

Figure 4. The "Yin and Yang" of oxygenation in the perioperative setting. In the clinical setting, utilizing high oxygen concentrations ("Hyperoxia") during the perioperative period or in critical care patients may be associated with an increased "safety margin" to avoid perioperative hypoxia and hypoxia-driven organ injury. However, hyperoxia has been implicated in promoting tissue injury by elevating levels of reactive oxygen species, and some clinical studies suggest worse outcomes associated with such approaches. At the same time, utilizing high inspired oxygen concentrations has the potential to dampen tissue-protective and anti-inflammatory pathways under the control of hypoxia-inducible transcription factors (HIFs), such as extracellular adenosine signaling. There appears to be a "Yin and Yang" with a U-shaped relationship between hyperoxia and conservative oxygen therapy. It will be critical for the perioperative field to find the "optimal oxygen concentration" for individual clinical scenarios. Different clinical studies have indicated that conservative oxygen therapy can be utilized safely in surgical or critical care patients, without increasing the risk of organ injury or wound infections. While we are awaiting the results of larger scale trials, the current evidence indicates oxygen conservative therapy as safe and associated with better outcomesat least in some of the measurements. In the context of the current review, some of the improved outcomes with conservative oxygen therapy could potentially be mediated by a more robust activation of the "HIF" pathway and concomitant organ protection.

HIFs and its concomitant role in promoting adenosine signaling and could therefore be detrimental. These findings would advise against the excessive use of high oxygen concentration in clinical settings as a supporting treatment of ARDS because superoxygenation might lead to increased mortality due to attenuated HIF responses.

The feasibility and safety of conservative oxygenation during the intraoperative phase have been investigated by several clinical studies. For instance, a randomized controlled trial conducted by Smit et $\mathrm{al}^{88}$ evaluated the effect of near-physiological oxygen targets on myocardial damage, organ function, and oxidative stress compared to standard care during and after coronary artery bypass surgery. In this study, a total of 50 patients were enrolled and randomized to receive conventional oxygenation ( $\mathrm{PaO}_{2}$ target of $200-220 \mathrm{~mm} \mathrm{Hg}$ during cardiopulmonary bypass and $130-150 \mathrm{~mm} \mathrm{Hg}$ during intensive care unit [ICU] admission) or near-physiological oxygenation $\left(\mathrm{PaO}_{2}\right.$ target of 130-150 mm $\mathrm{Hg}$ during cardiopulmonary bypass and $80-100 \mathrm{~mm} \mathrm{Hg}$ during ICU). The study concluded that conservative oxygen administration was not associated 
with increased lactate levels or hypoxic events during surgery and ICU stay, supporting the safety and feasibility for conservative intraoperative oxygenation. Additionally, the PROXI randomized clinical trial (NCT00364741) suggested that when compared with conservative perioperative oxygen fraction $(30 \%)$, high perioperative oxygen fraction $(80 \%)$ offers no benefit on surgical outcome, as marked by the incidence of surgical site infection and secondary pulmonary complications. ${ }^{89}$ All things considered, conservative oxygenation during surgery seems to be safe and feasible, and further study is needed to identify the impact of conservative oxygenation on perioperative outcomes.

The feasibility and safety of conservative oxygenation in the ICU has also been supported by several clinical studies. ${ }^{90,91}$ Furthermore, the beneficial effect of conservative oxygenation in the ICU was shown by a recent clinical trial by Girardis et al. ${ }^{92}$ In this trial, a total of 434 patients with a minimum duration of 72 hours in ICU randomly received either conventional (target peripheral capillary oxygen saturaton $\left[\mathrm{Spo}_{2}\right]$ 97\%-100\%) or conservative (target $\mathrm{SpO}_{2}$ 94\%-98\%) oxygen therapy. For both, in the context of ICU mortality and the occurrence of new organ failure and infection, patients in the conservative study arm showed better results. Results from all these pilot studies mentioned above justified the conduction of larger randomized controlled trials. Indeed, a phase III clinical trial (NCT02713451) is currently recruiting to test whether restrictive oxygenation could lower the 28-day mortality of ARDS patients in the ICU when compared with liberal oxygenation therapy. In summary, conservative oxygenation seems to be safe and feasible during ICU stays with further study ongoing to support the beneficial effect on patient outcomes.

The use of oxygen in the management of patients experiencing MI has been under debate for decades. Once considered the standard treatment for patients experiencing MI, the beneficial effect of oxygen supplementation to improve myocardial oxygenation and reduce infarct size has not been proven by evidence-based studies. ${ }^{93}$ It is unarguable that in certain patients with profound hypoxemia, oxygen supplementation would be crucial to maintain physiological oxygen levels. However, excess use of oxygen could potentially be detrimental in MI patients without hypoxemia because hyperoxia might raise blood pressure, lower myocardial oxygen delivery, and capillary density. ${ }^{94}$ A meta-analysis by Cabello et al $^{95}$ summarized 3 trials involving 387 patients and suggested the lack of evidence to support oxygen supplementation in the improvement of patient mortality. In addition, the air verses oxygen in myocardial infarction study (AVOID) clinical trial investigators (NCT01272713) analyzed the clinical outcomes of 441 patients with ST segment elevation MI receiving air or oxygen supplementation. ${ }^{96}$ Indeed, patients with supplemental oxygen displayed increases in peak creatine kinase level, incidence of recurrent MI, and frequency of cardiac arrhythmia. Large-scale clinical trials would be essential to evaluate the proper oxygen supplementation in the management of MI patients, while currently the clinical guideline has been evolving and suggested oxygen supplementation only in patients with hypoxemia.

In summary, the safety and efficiency of conservative oxygen therapy in surgical and critical care patients have been established by clinical studies and in the meantime implying that hyperoxia might be "too much of a good thing" under certain circumstances. For instance, intraoperative oxidative stress was implicated as a predictor for the development of AKI in patients with cardiac surgery. ${ }^{97}$ Moreover, the association between hyperoxia $\left(\mathrm{PaO}_{2} \geq 300 \mathrm{~mm} \mathrm{Hg}\right)$ and increased in-hospital mortality has been established by Kilgannon et $\mathrm{al}^{98}$ in patients after resuscitation from cardiac arrest. A recent systemic review and meta-analysis by Damiani et al summarized total of 6 clinical studies in patients postcardiac arrest and demonstrated an association between hyperoxia and increased mortality, despite the heterogeneity of the included studies. In the context of the current review, it is important to point out that hyperoxia may potentially dampen endogenous tissue-protective responses that are under the control of HIFs. While we are awaiting the results of larger scale trials, the current evidence points toward a more conservative oxygen therapy as safe and associated with better outcomes-at least in some of the measurements. In conclusion, it will be critical for the perioperative field to find the "optimal oxygen concentration" for individual clinical scenarios to improve surgical outcomes and to prevent perioperative organ injury.

\section{ACUTE KIDNEY INJURY}

AKI is clinically characterized by decreased urine output, increased serum creatinine levels, and decreased glomerular filtration rates. Kidney ischemia caused by reduction of renal blood flow that results in AKI can especially occur after surgical procedures. ${ }^{100}$ In addition, infection, anemia, and low cardiac output can also cause AKI. The incidence of AKI is estimated to be only $1 \%$ in patients receiving general surgical procedures, but strikingly the mortality rate of perioperative AKI is at $42 \%$, according to a recent cohort analysis of 75952 patients. ${ }^{101}$ The primary goal in approaching perioperative AKI is to prevent further insult by mitigating possible causes of AKI and preventing further renal damage from nephrotoxic drugs. ${ }^{102}$ To date, most therapeutic approaches to prevent or treat AKI have been deemed unsuccessful or even harmful, as the majority of interventional clinical trials in AKI have failed. ${ }^{103,104}$ The most recent Cochrane analysis regarding perioperative AKI found a significant amount of heterogeneity in patients' responses and failed AKI protection in a number of studied interventions, including dopamine and dopamine analogues, diuretics, calcium channel blockers, angiotensin-converting enzyme inhibitor drugs, $N$-acetyl cysteine, sodium bicarbonate, antioxidants, erythropoietin, and IV fluid administration. ${ }^{105}$ Importantly, a multicenter, randomized RenalRIP trial demonstrated that RIPC leads to both short-term and long-term postoperative kidney protection in patients undergoing high-risk cardiac surgery, ${ }^{106,107}$ although large-scale multicenter trials are crucial to optimize the RIPC protocol for efficient renal protection. ${ }^{108}$

The adaptive response to hypoxia leads to the stabilization of HIF via inhibition of PHDs, which is also observed in renal hypoxia and ischemia-/reperfusion-induced AKI. Several studies have demonstrated HIF stabilization and induction of HIF-dependent genes in renal protection 
during AKI. ${ }^{109}$ For instance, human renal tubular cells obtained from renal transplants were found to express increased levels of HIF- $1 \alpha$, which were positively correlated with better clinical outcome. ${ }^{110}$ Similarly, HIF accumulation was observed in wild-type mice exposed to no-flow ischemia-induced AKI, as well as in ischemic rat kidneys. ${ }^{36,111}$ To further illustrate the importance of HIF in the protection of AKI, studies have shown that the severity of ischemia/reperfusion injury in AKI is significantly increased in heterozygous HIF- $1 \alpha$-deficient mice. ${ }^{36}$ Additionally, a recent study demonstrated that endothelial-specific HIF-2 $\alpha$ expression exhibits a protective role in murine models of ischemia-/reperfusion-induced AKI. ${ }^{112}$ In search for HIFtargeting genes in renal cells, Yang and $\mathrm{Zou}^{113}$ identified heme oxygenase- 1 (HO-1) as an HIF-1 $\alpha$ gene target in renal medullary interstitial cells. The same group also demonstrated that induction of HO-1 significantly reduced oxidative stress-induced cell injury in human renal proximal tubular epithelial cells and that HO inhibitor, Tin protoporphyrin (SnPP), reversed this protection. ${ }^{114}$

Several preclinical studies have successfully demonstrated the effectiveness of HIF activators in the protection against ischemia-/reperfusion-induced AKI, suggesting the potential of utilizing pharmacological activation of HIF as therapeutic treatment. For example, HIF activator DMOG exhibited strong renal protection in a murine model of ischemic AKI. ${ }^{36}$ Ahn et $\mathrm{al}^{37}$ have also showed a similar result, demonstrating a renal protecting effect of DMOG in gentamicin-induced AKI. Indeed, DMOG treatment in vivo attenuated gentamicin-induced AKI by reducing renal dysfunction, proteinuria, and kidney pathology. Another study described that only pretreatment with DMOG confers renal protection while treatment during the early recovery phase of AKI does not confer renal protection, strongly suggesting the potential of HIF activators as preventative strategies. ${ }^{115}$ Treatment using a novel HIF hydroxylase inhibitor, TRC160334, also mediated protection against ischemic AKI in a rat model of ischemia-/reperfusion-induced AKI. ${ }^{116}$ Additionally, acetazolamide, commonly prescribed to treat glaucoma and high-altitude mountain sickness, is known to be a potent inducer of HIF-1 $\alpha .{ }^{117}$ Treatment with acetazolamide provided renal protection in a murine model of AKI, resulting in decreased creatinine and blood urea nitrogen levels. ${ }^{117}$ Furthermore, several clinical trials have tested the effect of HIF stabilization and/or PHD inhibition as treatment for anemic patients with renal injury. Taken together, it will be of great interest to test the safety and potential effectiveness of HIF activators in the prevention and treatment of AKI in clinical settings. Particularly, during surgical procedures with a high incidence of AKI, such as thoracoabdominal aortic aneurysm repair, HIF activators may potentially contribute significantly toward improving patient outcomes by preventing ischemia/reperfusion injury of the kidneys.

\section{ACUTE GUT INJURY}

The intestine plays a central role in promoting the transition from single organ injury to multiorgan failure in perioperative patients, and prevention of AGI is among the cornerstones in preventing multiorgan failure and sepsis. ${ }^{69,118,119}$ For example, experimental studies indicated that ischemic injury to the liver or the kidney will subsequently trigger intestinal dysfunction and a dramatic decrease in barrier function. ${ }^{120}$ Indeed, in vivo studies of acute kidney or liver ischemia revealed that distant organ ischemia could affect the physiologic functions of the intestine. ${ }^{120,121}$ This disturbed intestinal homeostasis affects the intestinal barrier function with mucosal disintegration, release of inflammatory mediators from Paneth cells, induction of mucosal inflammation, and translocation of intestinal microorganisms. Therefore, AGI-induced intestinal inflammation can facilitate systemic inflammation and, in patients at risk, favors the onset of sepsis and leads to multiple organ failures. It has been postulated that bacterial translocation from the intestinal lumen and release of mucosal microbiome contents are at least partially responsible. ${ }^{122,123}$ Extensive AGI can also be caused by mesenteric ischemia as a result of low-flow states, especially in surgeries utilizing aortic occlusion, cardiopulmonary bypass, or circulatory arrest, and potentially leads to significant hypoxia in the intestinal mucosa. The incidence of AGI ranges from $0.3 \%$ to $6.1 \%$ in patients undergoing cardiopulmonary bypass or lung transplant surgeries, and the frequency of mesenteric ischemia is estimated to be $0.15 \% .{ }^{124}$ Given the emergency nature of extensive AGI and its associated systemic inflammatory responses, the mortality of AGI is high, ranging from $18 \%$ to $58 \% .^{124,125}$

AGI is regularly accompanied by gastrointestinal (GI) inflammation, which can be associated with profound hypoxia, leading to HIF stabilization via post-translational modification by PHDs and to the release of adenosine into the lumen of the GI tract. Under pathological conditions, both HIF- $1 \alpha$ and HIF- $2 \alpha$ activation were observed in patients with intestinal inflammation, as well as in mice in experimental models of colitis. ${ }^{126-129}$ Interestingly, the function of HIFs, especially HIF- $1 \alpha$, was shown to be beneficial to improve disease outcome during gut inflammation., 6,130 For instance, tissue-specific deletions of HIF-1 $\alpha$ in intestinal epithelial cells resulted in increased intestinal inflammation and more severe disease during murine models of colitis. ${ }^{4,6,126,131,132}$ Particularly, HIF- $1 \alpha$ deletion was associated with profound weight loss, enhanced intestinal inflammation, and colonic shortening, all signs of exaggerated AGI and dysfunction. ${ }^{126}$ Consistently, deletion of VHL or PHD1, which results in increased HIF stabilization, was shown to be protective during intestinal inflammation. ${ }^{126,133}$ Moreover, mice with PHD1 deletion showed reduced susceptibility to the development of colitis as characterized by attenuated weight loss, lower levels of disease activity, improved colon histology, reduced neutrophil infiltration, and decreased cytokine expression. ${ }^{133}$ Collectively, HIF activation is essential in the control of GI inflammation.

Hypoxia-induced HIF stabilization leads to the activation of multiple target genes that are responsible for the protective function of HIF during intestinal inflammation. For example, in the absence of CD39, mice developed increased severity of experimental colitis. ${ }^{134}$ Similarly, genetic deletion of CD73 or administration of CD73 inhibitor $\alpha, \beta$-methylene ADP resulted in increased severity of trinitrobenzene sulfonateinduced murine colitis marked by increased weight loss and colonic shortening. ${ }^{135}$ Moreover, the protective role of CD73 in sepsis was supported by the observation of increased mortality in CD73-deficient mice after cecal ligation and puncture. ${ }^{136}$ Similar findings in models of intestinal ischemia/reperfusion 
injury highlighted functional roles of the CD39/CD73 pathway and signaling events through adenosine receptors in gut protection..$^{51,131,137} \mathrm{HIF}$ and its target gene CD73 also function through promoting regulatory $\mathrm{T}$ (Treg) cells during murine model of intestinal inflammation. ${ }^{138,139}$ Treg cells are a group of $\mathrm{CD}^{+} \mathrm{T}$ cells that dampen inflammation through inactivation of effector T cells. Additional studies identified forkhead box P3 (FOXP3) as a HIF-1 $\alpha$ target gene, suggesting the role of HIF-1 $\alpha$ in Treg cell functions in mitigating mucosal inflammation. ${ }^{138,140,141}$ For instance, deletion of HIF-1 $\alpha$ in Treg cells attenuated their capability to suppress gut inflammation in a $\mathrm{T}$ cell transfer model of intestinal inflammation. ${ }^{138}$ Similarly, and as seen in various acute organ injury models, adenosine signaling has anti-inflammatory effects through activating adenosine receptors, including $\mathrm{A} 2 \mathrm{AR}$ and $\mathrm{A} 2 \mathrm{BR}$ in GI inflammation. ${ }^{30}$ For instance, the transfer of A2AR-deficient CD45RB (low) CD25+ $^{+}$cells failed to block colitis induced by pathogenic CD45RB ${ }^{\text {(high) }} \mathrm{T}$ cells, and treatment with an A2AR agonist inhibited proinflammatory cytokine production. Additionally, the severity of dextran sodium sulfate-induced colitis was increased in A2BR-deficient mice compared to wild-type counterparts, suggesting the potential of adenosine receptor agonists as treatments for intestinal inflammation. ${ }^{142}$

Several studies have demonstrated that pharmacological compounds increasing HIF stabilization are beneficial during intestinal inflammation. For instance, mice treated with HIF activator DMOG showed profound improvements of multiple disease parameters, including weight loss, intestinal inflammation, and histologically observed tissue injury during chemically induced colitis. ${ }^{127}$ The beneficial effect of another PHD inhibitor, TRC160334, has also been demonstrated in both trinitrobenzene sulfonate-induced and dextran sodium sulfate-induced murine models of intestinal inflammation. TRC160334 treatment attenuated weight loss, reduced the overall disease activity index, and improved macroscopic and microscopic scores of colonic damage. ${ }^{143}$ Similarly, another PHD inhibitor, AKB-4924, has been shown to have significantly protective effects in murine models of intestinal inflammation ${ }^{144}$ or models of intestinal ischemia/reperfusion injury. ${ }^{131}$ In addition, a protective effect of A2BR agonist, BAY 60-6583 in acute intestinal inflammation has been demonstrated in experimental studies as well. ${ }^{145}$ Indeed, in murine models of acute intestinal inflammation, treatment with the specific A2BR adenosine receptor agonist BAY 60-6583 mediated mucosal protection characterized by attenuated colonic shortening, reduced tissue cytokines, and improved histological scores. Notably, the safety of oral PHD inhibitors, AKB-6548 and FG-4592, has been strongly supported by several clinical trials for renal diseases (Table). Thus, the potential use of oral delivery of HIF stabilizers could represent a safe and novel therapeutic approach for AGI. As such, this local administration approach may limit potential side effects from systemic administration of HIF activators.

\section{PHARMACOLOGIC HIF ACTIVATORS}

HIF activation can be achieved by inhibition of PHDs, which leads to HIF stabilization under normoxic conditions. There are several classes of compounds to inhibit the function of PHDs by preventing the binding of cosubstrate 2-OG, including iron chelators, CUL2 deneddylators and 2-OG mimics. ${ }^{4}$
For instance, DMOG mimics the structure of 2-OG and has been shown to inhibit the function of PHDs in several animal models, as mentioned in previous paragraphs. Oral application of these 3 HIF activators is currently being trialed in the clinical settings: vadadustat (AKB-6548, sponsored by Akebia, Cambridge, MA), roxadustat (FG-4592, sponsored by FibroGen, San Francisco, CA; Astellas, Northbrook, IL; and AstraZeneca, Wilmington, DE), and daprodustat (GSK1278863, sponsored by GlaxoSmithKline, Philadelphia, PA). The length of clinical trials of PHD inhibitors varies from 4 to 52 weeks. Once-daily oral administration of vadadustat has been shown to be effective in maintaining and increasing hemoglobin level after 2 weeks of treatment, as represented in a phase-2b study to test vadadustat as anemia treatment in nondialysis-dependent chronic kidney disease. ${ }^{146}$ Additionally, a phase-2 clinical study by Besarab et al ${ }^{147}$ implicated that the time to respond to biweekly oral application of roxadustat ranges from 14 to 21 days in patients treated with higher dose of roxadustat $(2 \mathrm{mg} / \mathrm{kg})$, as marked by increases in hemoglobin levels. Collectively, oral available PHD inhibitors have been assessed in clinical settings to be effective as treatment of anemia in chronic kidney disease patients, and it is reasonable to pursue PHD inhibitors as a novel therapeutic approach for perioperative organ injury.

Given the diverse functions of HIF in a multitude of developmental, physiological, and pathophysiological processes, altering such a pathway has its own limitations, especially in chronic setting. Several concerns of HIF activators have been raised from basic research and preclinical studies. For example, Xue et al ${ }^{148}$ demonstrated that HIF-2 $\alpha$ activation via disruption of VHL promoted colorectal cancer progression in mice. Additional study in murine model of tubulointerstitial fibrosis indicated that HIF activation might have a detrimental impact on the development of fibrosis. ${ }^{149}$ Fortunately, the safety of PHD inhibitors in patients has been established by several phase-2 clinical studies. ${ }^{146,147,150,151}$ However, 1 of the first-generation PHD inhibitor, FG-2216, was related to the development of fatal hepatic necrosis in 1 patient. Due to the single death event and abnormal liver enzyme test results from other patients, the phase-2 clinical trial of FG-2216 has to be suspended. Since the discontinuation of studies in FG-2216, FibroGen developed a second-generation PHD inhibitor-roxadustat, and no significant hepatic adverse effect was observed in a phase- $2 b$ clinical study in patients with chronic kidney disease, suggesting that the case of hepatic necrosis related to FG-2216 might be an off-target effect. Another concern of the application of PHD inhibitor in the clinical settings involves the impact of HIF activation on erythropoiesis. Although increased erythropoietin expression is desirable for treatment of conditions such as renal anemia, increased risk of thromboembolic events can serve as an undesirable adverse effect. However, it is quite reassuring that recent trials of vadadustat and roxadustat showed no increase in the incidence of hypertension and cardiovascular events. ${ }^{146,150}$ In addition, HIFs can stimulate vascular endothelial growth factor (VEGF) release accompanied by increased vascular leakage; however, the concern of HIF activator-related VEGF release was alleviated by an encouraging phase-2 study to test the efficacy of daprodustat on anemia management. ${ }^{151}$ Indeed, there is no change observed in the level of circulating VEGF in the daprodustat treatment group 
compared with placebo control. Meanwhile, the number of clinical trials for HIF activators as therapeutic interventions for perioperative organ injury has been thus far limited when compared with clinical trials in renal anemia. We believe that the primary reason for the lack of clinical trials could be that the tissue-protective effects of HIF activation in acute organ injury have only been recently discovered. Indeed, the relationship between HIF and erythropoietin and the important protective effects of this association was established decades ago. Further research in the protective effect of HIF activation in acute organ injury will facilitate our understanding of the mechanisms of action, which will avoid or minimize potential side effects from the treatment with HIF activators in perioperative settings. Taken together, the safety of HIF activation by PHD inhibitors is reassured by several clinical studies, and short-term use of HIF activators in perioperative medicine appears safe based on the safety records using HIF activators over extended time periods.

\section{CONCLUSIONS}

Perioperative organ injury is considered 1 of the leading causes of perioperative morbidity and mortality, and there is urgent need for the development of novel therapies for organ protection in surgical patients. Hypoxia signaling serves a protective role in multiple types of perioperative organ injuries, including MI, ARDS, AKI, and AGI. It is important to note that these responses and the ultimate stabilization of HIF are considered adaptive to physiologic insult and that attempting to modulate them clinically by inducing hypoxia or inflammation would be inadvisable. However, targeting hypoxia signaling via HIF activators (in the absence of the physiologic insult) appears to be promising with a good safety profile of existing oral agents and the emergence of newer compounds on the horizon. In addition to potential benefits in perioperative organ injury, there may be additional advantageous effects of these agents. HIF activators also drive the expression of erythropoietin and increase red blood cell counts, a condition surgical patients could profit from by reducing their need for blood products and preventing transfusion-associated complications as well. Given the elective nature of most surgeries, HIF activators can possibly be administered preoperatively to induce the full potential of the beneficial effects. Besides HIF activation by PHD inhibitors, pharmacologic enhancers of HIF target genes can also be used to prevent perioperative organ injury. For instance, A2BR receptor agonists and small interfering RNA for PHDs or HIF target genes could represent novel therapeutic targets for perioperative organ injury. However, the study of novel therapeutic approaches targeting hypoxia signaling is still in its infancy because of the lack of clinical studies focusing on this area. From this clinical perspective, it will be crucial to promote these novel therapeutic approaches by performing additional clinical trials and by increasing our understanding of the mechanisms of action, thereby eliminating possible safety concerns that hinder the progress from bench to bedside. Additionally, further knowledge identifying patient populations at higher risk for specific type of perioperative organ injuries will allow for more targeted therapeutic approaches, ultimately allowing for a cost-effective and personalized approach to perioperative organ protection. $\#$

\section{DISCLOSURES}

Name: Xiaoyi Yuan, PhD.

Contribution: This author helped draft and finalize the manuscript.

Name: Jae W. Lee, MD.

Contribution: This author helped revise the manuscript.

Name: Jessica L. Bowser, PhD.

Contribution: This author helped revise the manuscript.

Name: Viola Neudecker, MD.

Contribution: This author helped revise the manuscript.

Name: Srikanth Sridhar, MD.

Contribution: This author helped revise the manuscript.

Name: Holger K. Eltzschig, MD, PhD.

Contribution: This author helped revise the manuscript and provide critical advice on the structure and content of the manuscript. This manuscript was handled by: Alexander Zarbock, MD.

\section{REFERENCES}

1. Semel ME, Lipsitz SR, Funk LM, Bader AM, Weiser TG, Gawande AA. Rates and patterns of death after surgery in the United States, 1996 and 2006. Surgery. 2012;151:171-182.

2. Kork F, Balzer F, Spies CD, et al. Minor postoperative increases of creatinine are associated with higher mortality and longer hospital length of stay in surgical patients. Anesthesiology. 2015;123:1301-1311.

3. Eltzschig HK, Carmeliet P. Hypoxia and inflammation. $N$ Engl J Med. 2011;364:656-665.

4. Eltzschig HK, Bratton DL, Colgan SP. Targeting hypoxia signalling for the treatment of ischaemic and inflammatory diseases. Nat Rev Drug Discov. 2014;13:852-869.

5. Eltzschig HK, Eckle T. Ischemia and reperfusion-from mechanism to translation. Nat Med. 2011;17:1391-1401.

6. Colgan SP, Eltzschig HK. Adenosine and hypoxia-inducible factor signaling in intestinal injury and recovery. Annu Rev Physiol. 2012;74:153-175.

7. Eckle T, Brodsky K, Bonney M, et al. HIF1A reduces acute lung injury by optimizing carbohydrate metabolism in the alveolar epithelium. PLoS Biol. 2013;11:e1001665.

8. Campbell EL, Bruyninckx WJ, Kelly CJ, et al. Transmigrating neutrophils shape the mucosal microenvironment through localized oxygen depletion to influence resolution of inflammation. Immunity. 2014;40:66-77.

9. Beutler B. Tlr4: central component of the sole mammalian LPS sensor. Curr Opin Immunol. 2000;12:20-26.

10. Hartmann H, Eltzschig HK, Wurz H, et al. Hypoxiaindependent activation of HIF-1 by enterobacteriaceae and their siderophores. Gastroenterology. 2008;134:756-767.

11. Peyssonnaux C, Cejudo-Martin P, Doedens A, Zinkernagel AS, Johnson RS, Nizet V. Cutting edge: essential role of hypoxia inducible factor-1alpha in development of lipopolysaccharideinduced sepsis. J Immunol. 2007;178:7516-7519.

12. Bartels K, Karhausen J, Clambey ET, Grenz A, Eltzschig HK. Perioperative organ injury. Anesthesiology. 2013;119:1474-1489.

13. Wang GL, Semenza GL. Purification and characterization of hypoxia-inducible factor 1. J Biol Chem. 1995;270:1230-1237.

14. Wang GL, Jiang BH, Rue EA, Semenza GL. Hypoxia-inducible factor 1 is a basic-helix-loop-helix-PAS heterodimer regulated by cellular O2 tension. Proc Natl Acad Sci U S A. 1995;92:5510-5514.

15. Ohh M, Park CW, Ivan M, et al. Ubiquitination of hypoxiainducible factor requires direct binding to the beta-domain of the von Hippel-Lindau protein. Nat Cell Biol. 2000;2:423-427.

16. Ivan M, Kondo K, Yang H, et al. HIFalpha targeted for VHLmediated destruction by proline hydroxylation: implications for O2 sensing. Science. 2001;292:464-468.

17. Jaakkola P, Mole DR, Tian YM, et al. Targeting of HIF-alpha to the von Hippel-Lindau ubiquitylation complex by O2-regulated prolyl hydroxylation. Science. 2001;292:468-472.

18. Semenza GL, Nejfelt MK, Chi SM, Antonarakis SE. Hypoxiainducible nuclear factors bind to an enhancer element located $3^{\prime}$ to the human erythropoietin gene. Proc Natl Acad Sci U S A. 1991;88:5680-5684.

19. Semenza GL, Wang GL. A nuclear factor induced by hypoxia via de novo protein synthesis binds to the human erythropoietin gene enhancer at a site required for transcriptional activation. Mol Cell Biol. 1992;12:5447-5454. 
20. Malik M, Poloniecki J. Myths of risk stratification. Pacing Clin Electrophysiol. 1992;15:361-366.

21. Buckley CD, Gilroy DW, Serhan CN. Proresolving lipid mediators and mechanisms in the resolution of acute inflammation. Immunity. 2014;40:315-327.

22. Hart ML, Gorzolla IC, Schittenhelm J, Robson SC, Eltzschig HK. SP1-dependent induction of CD39 facilitates hepatic ischemic preconditioning. J Immunol. 2010;184:4017-4024.

23. Synnestvedt K, Furuta GT, Comerford KM, et al. Ecto-5'nucleotidase (CD73) regulation by hypoxia-inducible factor-1 mediates permeability changes in intestinal epithelia. J Clin Invest. 2002;110:993-1002.

24. Cronstein BN, Daguma L, Nichols D, Hutchison AJ, Williams $\mathrm{M}$. The adenosine/neutrophil paradox resolved: human neutrophils possess both A1 and A2 receptors that promote chemotaxis and inhibit $\mathrm{O} 2$ generation, respectively. J Clin Invest. 1990;85:1150-1157.

25. Wallace KL, Linden J. Adenosine A2A receptors induced on iNKT and NK cells reduce pulmonary inflammation and injury in mice with sickle cell disease. Blood. 2010;116:5010-5020.

26. Yang Z, Day YJ, Toufektsian MC, et al. Infarct-sparing effect of A2A-adenosine receptor activation is due primarily to its action on lymphocytes. Circulation. 2005;111:2190-2197.

27. Haskó G, Pacher P. A2A receptors in inflammation and injury: lessons learned from transgenic animals. J Leukoc Biol. 2008;83:447-455.

28. Eckle T, Hartmann K, Bonney S, et al. Adora2b-elicited Per2 stabilization promotes a HIF-dependent metabolic switch crucial for myocardial adaptation to ischemia. Nat Med. 2012;18:774-782.

29. Eckle T, Faigle M, Grenz A, Laucher S, Thompson LF, Eltzschig HK. A2B adenosine receptor dampens hypoxia-induced vascular leak. Blood. 2008;111:2024-2035.

30. Naganuma M, Wiznerowicz EB, Lappas CM, Linden J, Worthington MT, Ernst PB. Cutting edge: critical role for A2A adenosine receptors in the T cell-mediated regulation of colitis. J Immunol. 2006;177:2765-2769.

31. Frick JS, MacManus CF, Scully M, Glover LE, Eltzschig HK, Colgan SP. Contribution of adenosine A2B receptors to inflammatory parameters of experimental colitis. J Immunol. 2009;182:4957-4964.

32. Eltzschig HK, Sitkovsky MV, Robson SC. Purinergic signaling during inflammation. N Engl J Med. 2012;367:2322-2333.

33. Eltzschig HK, Köhler D, Eckle T, Kong T, Robson SC, Colgan SP. Central role of Sp1-regulated CD39 in hypoxia/ischemia protection. Blood. 2009;113:224-232.

34. Eckle T, Kewley EM, Brodsky KS, et al. Identification of hypoxia-inducible factor HIF-1A as transcriptional regulator of the A2B adenosine receptor during acute lung injury. J Immunol. 2014;192:1249-1256.

35. Ahmad A, Ahmad S, Glover L, et al. Adenosine A2A receptor is a unique angiogenic target of HIF-2alpha in pulmonary endothelial cells. Proc Natl Acad Sci U S A. 2009;106:10684-10689.

36. Hill P, Shukla D, Tran MG, et al. Inhibition of hypoxia inducible factor hydroxylases protects against renal ischemia-reperfusion injury. J Am Soc Nephrol. 2008;19:39-46.

37. Ahn JM, You SJ, Lee YM, et al. Hypoxia-inducible factor activation protects the kidney from gentamicin-induced acute injury. PLoS One. 2012;7:e48952.

38. McDonough MA, Li V, Flashman E, et al. Cellular oxygen sensing: crystal structure of hypoxia-inducible factor prolyl hydroxylase (PHD2). Proc Natl Acad Sci U S A. 2006;103:9814-9819.

39. Fong GH, Takeda K. Role and regulation of prolyl hydroxylase domain proteins. Cell Death Differ. 2008;15:635-641.

40. Rajan P, Greenberg H. Obstructive sleep apnea as a risk factor for type 2 diabetes mellitus. Nat Sci Sleep. 2015;7:113-125.

41. Cheng K, Ho K, Stokes R, et al. Hypoxia-inducible factor1alpha regulates beta cell function in mouse and human islets. J Clin Invest. 2010;120:2171-2183.

42. Thygesen K, Alpert JS, Jaffe AS, et al; Joint ESC/ACCF/AHA/ WHFTask Force for Universal Definition of Myocardial Infarction; Authors/Task Force Members Chairpersons; Biomarker Subcommittee; ECG Subcommittee; Imaging Subcommittee; Classification Subcommittee; Intervention Subcommittee; Trials
\& Registries Subcommittee; Trials \& Registries Subcommittee; Trials \& Registries Subcommittee; Trials \& Registries Subcommittee; ESC Committee for Practice Guidelines (CPG); Document Reviewers. Third universal definition of myocardial infarction. I Am Coll Cardiol. 2012;60:1581-1598.

43. Lee TH, Marcantonio ER, Mangione CM, et al. Derivation and prospective validation of a simple index for prediction of cardiac risk of major noncardiac surgery. Circulation. 1999;100:1043-1049.

44. Devereaux PJ, Xavier D, Pogue J, et al; POISE (PeriOperative ISchemic Evaluation) Investigators. Characteristics and shortterm prognosis of perioperative myocardial infarction in patients undergoing noncardiac surgery: a cohort study. Ann Intern Med. 2011;154:523-528.

45. Devereaux PJ, Goldman L, Yusuf S, Gilbert K, Leslie K, Guyatt GH. Surveillance and prevention of major perioperative ischemic cardiac events in patients undergoing noncardiac surgery: a review. CMAJ. 2005;173:779-788.

46. Davies MJ, Thomas AC. Plaque fissuring - the cause of acute myocardial infarction, sudden ischaemic death, and crescendo angina. Br Heart J. 1985;53:363-373.

47. Adluri RS, Thirunavukkarasu M, Dunna NR, et al. Disruption of hypoxia-inducible transcription factor-prolyl hydroxylase domain-1 (PHD-1-/-) attenuates ex vivo myocardial ischemia/ reperfusion injury through hypoxia-inducible factor- $1 \alpha$ transcription factor and its target genes in mice. Antioxid Redox Signal. 2011;15:1789-1797.

48. Eltzschig HK, Bonney SK, Eckle T. Attenuating myocardial ischemia by targeting A2B adenosine receptors. Trends Mol Med. 2013;19:345-354.

49. Eltzschig HK. Adenosine: an old drug newly discovered. Anesthesiology. 2009;111:904-915.

50. Bauerle JD, Grenz A, Kim JH, Lee HT, Eltzschig HK. Adenosine generation and signaling during acute kidney injury. J Am Soc Nephrol. 2011;22:14-20.

51. Hart ML, Henn M, Köhler D, et al. Role of extracellular nucleotide phosphohydrolysis in intestinal ischemia-reperfusion injury. FASEB J. 2008;22:2784-2797.

52. Hart ML, Much C, Gorzolla IC, et al. Extracellular adenosine production by ecto- 5 '-nucleotidase protects during murine hepatic ischemic preconditioning. Gastroenterology. 2008;135:1739-1750.e3.

53. Eckle T, Koeppen M, Eltzschig HK. Role of extracellular adenosine in acute lung injury. Physiology (Bethesda). 2009;24:298-306.

54. Eltzschig HK, Macmanus CF, Colgan SP. Neutrophils as sources of extracellular nucleotides: functional consequences at the vascular interface. Trends Cardiovasc Med. 2008;18:103-107.

55. Eckle T, Krahn T, Grenz A, et al. Cardioprotection by ecto-5'-nucleotidase (CD73) and $\mathrm{A} 2 \mathrm{~B}$ adenosine receptors. Circulation. 2007;115:1581-1590.

56. Ali ZA, Callaghan CJ, Lim E, et al. Remote ischemic preconditioning reduces myocardial and renal injury after elective abdominal aortic aneurysm repair: a randomized controlled trial. Circulation. 2007;116:198-105.

57. Cai Z, Luo W, Zhan H, Semenza GL. Hypoxia-inducible factor 1 is required for remote ischemic preconditioning of the heart. Proc Natl Acad Sci U S A. 2013;110:17462-17467.

58. Sarkar K, Cai Z, Gupta R, et al. Hypoxia-inducible factor 1 transcriptional activity in endothelial cells is required for acute phase cardioprotection induced by ischemic preconditioning. Proc Natl Acad Sci U S A. 2012;109:10504-10509.

59. Ockaili R, Natarajan R, Salloum F, et al. HIF-1 activation attenuates postischemic myocardial injury: role for heme oxygenase-1 in modulating microvascular chemokine generation. Am J Physiol Heart Circ Physiol. 2005;289:H542-H548.

60. Eckle T, Köhler D, Lehmann R, El Kasmi K, Eltzschig HK. Hypoxia-inducible factor- 1 is central to cardioprotection: a new paradigm for ischemic preconditioning. Circulation. 2008;118:166-175.

61. Gerczuk PZ, Kloner RA. An update on cardioprotection: a review of the latest adjunctive therapies to limit myocardial infarction size in clinical trials. J Am Coll Cardiol. 2012;59:969-978.

62. Ross AM, Gibbons RJ, Stone GW, Kloner RA, Alexander RW; AMISTAD-II Investigators. A randomized, double-blinded, 
placebo-controlled multicenter trial of adenosine as an adjunct to reperfusion in the treatment of acute myocardial infarction (AMISTAD-II). J Am Coll Cardiol. 2005;45:1775-1780.

63. Kloner RA, Forman MB, Gibbons RJ, Ross AM, Alexander RW, Stone GW. Impact of time to therapy and reperfusion modality on the efficacy of adenosine in acute myocardial infarction: the AMISTAD-2 trial. Eur Heart J. 2006;27:2400-2405.

64. Ranieri VM, Rubenfeld GD, Thompson BT, et al; ARDS Definition Task Force. Acute respiratory distress syndrome: the Berlin Definition. JAMA. 2012;307:2526-2533.

65. Gajic O, Dabbagh O, Park PK, et al; U.S. Critical Illness and Injury Trials Group: Lung Injury Prevention Study Investigators (USCIITG-LIPS). Early identification of patients at risk of acute lung injury: evaluation of lung injury prediction score in a multicenter cohort study. Am J Respir Crit Care Med. 2011;183:462-470.

66. Blum JM, Stentz MJ, Dechert R, et al. Preoperative and intraoperative predictors of postoperative acute respiratory distress syndrome in a general surgical population. Anesthesiology. 2013;118:19-29.

67. Dulu A, Pastores SM, Park B, Riedel E, Rusch V, Halpern NA. Prevalence and mortality of acute lung injury and ARDS after lung resection. Chest. 2006;130:73-78.

68. Wheeler AP, Bernard GR. Acute lung injury and the acute respiratory distress syndrome: a clinical review. Lancet. 2007;369:1553-1564.

69. Idzko M, Ferrari D, Eltzschig HK. Nucleotide signalling during inflammation. Nature. 2014;509:310-317.

70. Koeppen M, Eckle T, Eltzschig HK. The hypoxia-inflammation link and potential drug targets. Curr Opin Anaesthesiol. 2011;24:363-369.

71. Koeppen M, Eckle T, Eltzschig HK. Interplay of hypoxia and A2B adenosine receptors in tissue protection. Adv Pharmacol. 2011;61:145-186.

72. Aherne CM, Kewley EM, Eltzschig HK. The resurgence of A2B adenosine receptor signaling. Biochim Biophys Acta. 2011;1808:1329-1339.

73. Zhaosheng J, Ka Chun S, Daqing M. Perioperative remote acute lung injury: recent update. J Biomed Res. 201719 Jan [Epub ahead of print].

74. Tremblay LN, Slutsky AS. Ventilator-induced lung injury: from the bench to the bedside. Intensive Care Med. 2006;32:24-33.

75. Brower RG, Matthay MA, Morris A, Schoenfeld D, Thompson BT, Wheeler A; Acute Respiratory Distress Syndrome Network. Ventilation with lower tidal volumes as compared with traditional tidal volumes for acute lung injury and the acute respiratory distress syndrome. N Engl J Med. 2000;342:1301-1308.

76. Steinberg KP, Hudson LD, Goodman RB, et al; National Heart, Lung, and Blood Institute Acute Respiratory Distress Syndrome (ARDS) Clinical Trials Network. Efficacy and safety of corticosteroids for persistent acute respiratory distress syndrome. $\mathrm{N}$ Engl J Med. 2006;354:1671-1684.

77. Rice TW, Wheeler AP, Thompson BT, deBoisblanc BP, Steingrub J, Rock P; NIH NHLBI Acute Respiratory Distress Syndrome Network of Investigators; NHLBI ARDS Clinical Trials Network. Enteral omega-3 fatty acid, gamma-linolenic acid, and antioxidant supplementation in acute lung injury. JAMA. 2011;306:1574-1581.

78. Eckle T, Füllbier L, Wehrmann M, et al. Identification of ectonucleotidases CD39 and CD73 in innate protection during acute lung injury. J Immunol. 2007;178:8127-8137.

79. Reutershan J, Vollmer I, Stark S, Wagner R, Ngamsri KC, Eltzschig HK. Adenosine and inflammation: CD39 and CD73 are critical mediators in LPS-induced PMN trafficking into the lungs. FASEB J. 2009;23:473-482.

80. Schingnitz U, Hartmann K, Macmanus CF, et al. Signaling through the $\mathrm{A} 2 \mathrm{~B}$ adenosine receptor dampens endotoxininduced acute lung injury. J Immunol. 2010;184:5271-5279.

81. Eckle T, Grenz A, Laucher S, Eltzschig HK. A2B adenosine receptor signaling attenuates acute lung injury by enhancing alveolar fluid clearance in mice. J Clin Invest. 2008;118:3301-3315.

82. Rosenberger P, Schwab JM, Mirakaj V, et al. Hypoxia-inducible factor-dependent induction of netrin-1 dampens inflammation caused by hypoxia. Nat Immunol. 2009;10:195-202.
83. Mirakaj V, Thix CA, Laucher S, et al. Netrin-1 dampens pulmonary inflammation during acute lung injury. Am J Respir Crit Care Med. 2010;181:815-824.

84. Hoegl S, Brodsky KS, Blackburn MR, Karmouty-Quintana H, Zwissler B, Eltzschig HK. Alveolar epithelial A2B adenosine receptors in pulmonary protection during acute lung injury. J Immunol. 2015;195:1815-1824.

85. Koscsó B, Trepakov A, Csóka B, et al. Stimulation of A2B adenosine receptors protects against trauma-hemorrhagic shockinduced lung injury. Purinergic Signal. 2013;9:427-432.

86. Helmerhorst HJ, Schultz MJ, van der Voort PH, de Jonge E, van Westerloo DJ. Bench-to-bedside review: the effects of hyperoxia during critical illness. Crit Care. 2015;19:284.

87. Thiel M, Chouker A, Ohta A, et al. Oxygenation inhibits the physiological tissue-protecting mechanism and thereby exacerbates acute inflammatory lung injury. PLoS Biol. 2005;3:e174.

88. Smit B, Smulders YM, de Waard MC, et al. Moderate hyperoxic versus near-physiological oxygen targets during and after coronary artery bypass surgery: a randomised controlled trial. Crit Care. 2016;20:55.

89. Meyhoff CS, Wetterslev J, Jorgensen LN, et al; PROXI Trial Group. Effect of high perioperative oxygen fraction on surgical site infection and pulmonary complications after abdominal surgery: the PROXI randomized clinical trial. JAMA. 2009;302:1543-1550.

90. Suzuki S, Eastwood GM, Glassford NJ, et al. Conservative oxygen therapy in mechanically ventilated patients: a pilot before-and-after trial. Crit Care Med. 2014;42:1414-1422.

91. Panwar R, Hardie M, Bellomo R, et al; CLOSE Study Investigators; ANZICS Clinical Trials Group. Conservative versus liberal oxygenation targets for mechanically ventilated patients. A pilot multicenter randomized controlled trial. Am J Respir Crit Care Med. 2016;193:43-51.

92. Girardis M, Busani S, Damiani E, et al. Effect of conservative vs conventional oxygen therapy on mortality among patients in an intensive care unit: the Oxygen-ICU Randomized Clinical Trial. JAMA. 2016;316:1583-1589.

93. Kones R. Oxygen therapy for acute myocardial infarction-then and now. A century of uncertainty. Am J Med. 2011;124:1000-1005.

94. Weston C. Oxygen therapy in acute myocardial infarctiontoo much of a good thing? Cochrane Database Syst Rev. 2010;2011:ED000006.

95. Cabello JB, Burls A, Emparanza JI, Bayliss S, Quinn T. Oxygen therapy for acute myocardial infarction. Cochrane Database Syst Rev. 2010:CD007160.

96. Stub D, Smith K, Bernard S, et al; AVOID Investigators. Air versus oxygen in ST-segment-elevation myocardial infarction. Circulation. 2015;131:2143-2150.

97. Billings FTt, Pretorius M, Schildcrout JS, et al. Obesity and oxidative stress predict AKI after cardiac surgery. J Am Soc Nephrol. 2012;23:1221-1228.

98. Kilgannon JH, Jones AE, Shapiro NI, et al; Emergency Medicine Shock Research Network (EMShockNet) Investigators. Association between arterial hyperoxia following resuscitation from cardiac arrest and in-hospital mortality. JAMA. 2010;303:2165-2171.

99. Damiani E, Adrario E, Girardis M, et al. Arterial hyperoxia and mortality in critically ill patients: a systematic review and meta-analysis. Crit Care. 2014;18(6):711.

100. Gelman S. The pathophysiology of aortic cross-clamping and unclamping. Anesthesiology. 1995;82:1026-1060.

101. Kheterpal S, Tremper KK, Heung M, et al. Development and validation of an acute kidney injury risk index for patients undergoing general surgery: results from a national data set. Anesthesiology. 2009;110:505-515.

102. Kellum JA, Lameire N; KDIGO AKI Guideline Work Group. Diagnosis, evaluation, and management of acute kidney injury: a KDIGO summary (Part 1). Crit Care. 2013;17:204.

103. Bove T, Landoni G, Calabrò MG, et al. Renoprotective action of fenoldopam in high-risk patients undergoing cardiac surgery: a prospective, double-blind, randomized clinical trial. Circulation. 2005;111:3230-3235.

104. Bellomo R, Chapman M, Finfer S, Hickling K, Myburgh J. Low-dose dopamine in patients with early renal dysfunction: 
a placebo-controlled randomised trial. Australian and New Zealand Intensive Care Society (ANZICS) Clinical Trials Group. Lancet. 2000;356:2139-2143.

105. Zacharias M, Mugawar M, Herbison GP, et al. Interventions for protecting renal function in the perioperative period. Cochrane Database Syst Rev. 2013:CD003590.

106. Zarbock A, Schmidt C, Van Aken H, et al; RenalRIPC Investigators. Effect of remote ischemic preconditioning on kidney injury among high-risk patients undergoing cardiac surgery: a randomized clinical trial. JAMA. 2015;313:2133-2141.

107. Zarbock A, Kellum JA, Van Aken H, et al. Long-term effects of remote ischemic preconditioning on kidney function in high-risk cardiac surgery patients: follow-up results from the RenalRIP trial. Anesthesiology. 2017;126:787-798.

108. Kork F, Eltzschig HK. The devil is in the detail: remote ischemic preconditioning for perioperative kidney protection. Anesthesiology. 2017;126:763-765.

109. Nangaku M, Rosenberger C, Heyman SN, Eckardt KU. Regulation of hypoxia-inducible factor in kidney disease. Clin Exp Pharmacol Physiol. 2013;40:148-157.

110. Conde E, Alegre L, Blanco-Sánchez I, et al. Hypoxia inducible factor 1-alpha (HIF-1 alpha) is induced during reperfusion after renal ischemia and is critical for proximal tubule cell survival. PLoS One. 2012;7:e33258.

111. Rosenberger C, Mandriota S, Jürgensen JS, et al. Expression of hypoxia-inducible factor-1alpha and -2alpha in hypoxic and ischemic rat kidneys. J Am Soc Nephrol. 2002;13:1721-1732.

112. Kapitsinou PP, Sano H, Michael M, et al. Endothelial HIF-2 mediates protection and recovery from ischemic kidney injury. J Clin Invest. 2014;124:2396-2409.

113. Yang ZZ, Zou AP. Transcriptional regulation of heme oxygenases by HIF-1alpha in renal medullary interstitial cells. Am J Physiol Renal Physiol. 2001;281:F900-F908.

114. Yang Y, Ohta K, Shimizu M, et al. Selective protection of renal tubular epithelial cells by heme oxygenase (HO)-1 during stress-induced injury. Kidney Int. 2003;64:1302-1309.

115. Kapitsinou PP, Jaffe J, Michael M, et al. Preischemic targeting of HIF prolyl hydroxylation inhibits fibrosis associated with acute kidney injury. Am J Physiol Renal Physiol. 2012;302:F1172-F1179.

116. Jamadarkhana P, Chaudhary A, Chhipa L, et al. Treatment with a novel hypoxia-inducible factor hydroxylase inhibitor (TRC160334) ameliorates ischemic acute kidney injury. Am J Nephrol. 2012;36:208-218.

117. An Y, Zhang JZ, Han J, et al. Hypoxia-inducible factor- $1 \alpha$ dependent pathways mediate the renoprotective role of acetazolamide against renal ischemia-reperfusion injury. Cell Physiol Biochem. 2013;32:1151-1166.

118. Idzko M, Ferrari D, Riegel AK, Eltzschig HK. Extracellular nucleotide and nucleoside signaling in vascular and blood disease. Blood. 2014;124:1029-1037.

119. Chen JF, Eltzschig HK, Fredholm BB. Adenosine receptors as drug targets-what are the challenges? Nat Rev Drug Discov. 2013;12:265-286.

120. Park SW, Kim M, Brown KM, D'Agati VD, Lee HT. Paneth cell-derived interleukin-17A causes multiorgan dysfunction after hepatic ischemia and reperfusion injury. Hepatology. 2011;53:1662-1675.

121. Park SW, Chen SW, Kim M, et al. Cytokines induce small intestine and liver injury after renal ischemia or nephrectomy. Lab Invest. 2011;91:63-84.

122. Deitch EA. Gut lymph and lymphatics: a source of factors leading to organ injury and dysfunction. Ann N Y Acad Sci. 2010;1207(suppl 1):E103-E111.

123. Ohri SK, Velissaris T. Gastrointestinal dysfunction following cardiac surgery. Perfusion. 2006;21:215-223.

124. Rodriguez R, Robich MP, Plate JF, Trooskin SZ, Sellke FW. Gastrointestinal complications following cardiac surgery: a comprehensive review. J Card Surg. 2010;25:188-197.

125. Lahon B, Mordant P, Thabut G, et al. Early severe digestive complications after lung transplantation. Eur J Cardiothorac Surg. 2011;40:1419-1424.
126. Karhausen J, Furuta GT, Tomaszewski JE, Johnson RS, Colgan SP, Haase VH. Epithelial hypoxia-inducible factor-1 is protective in murine experimental colitis. J Clin Invest. 2004;114:1098-1106.

127. Cummins EP, Seeballuck F, Keely SJ, et al. The hydroxylase inhibitor dimethyloxalylglycine is protective in a murine model of colitis. Gastroenterology. 2008;134:156-165.

128. Morote-Garcia JC, Rosenberger P, Nivillac NM, Coe IR, Eltzschig HK. Hypoxia-inducible factor-dependent repression of equilibrative nucleoside transporter 2 attenuates mucosal inflammation during intestinal hypoxia. Gastroenterology. 2009;136:607-618.

129. Robinson A, Keely S, Karhausen J, Gerich ME, Furuta GT, Colgan SP. Mucosal protection by hypoxia-inducible factor prolyl hydroxylase inhibition. Gastroenterology. 2008;134:145-155.

130. Taylor CT, Colgan SP. Hypoxia and gastrointestinal disease. J Mol Med (Berl). 2007;85:1295-1300.

131. Hart ML, Grenz A, Gorzolla IC, Schittenhelm J, Dalton JH, Eltzschig HK. Hypoxia-inducible factor-1 $\alpha$-dependent protection from intestinal ischemia/reperfusion injury involves ecto-5'-nucleotidase (CD73) and the A2B adenosine receptor. $J$ Immunol. 2011;186:4367-4374

132. Taylor CT, Colgan SP. Hypoxia and gastrointestinal disease. J Mol Med (Berl). 2007;85:1295-1300.

133. Tambuwala MM, Cummins EP, Lenihan CR, et al. Loss of prolyl hydroxylase- 1 protects against colitis through reduced epithelial cell apoptosis and increased barrier function. Gastroenterology. 2010;139:2093-2101.

134. Friedman DJ, Künzli BM, A-Rahim YI et al. From the Cover: CD39 deletion exacerbates experimental murine colitis and human polymorphisms increase susceptibility to inflammatory bowel disease. Proc Natl Acad Sci U S A. 2009;106:16788-16793.

135. Louis NA, Robinson AM, MacManus CF, Karhausen J, Scully M, Colgan SP. Control of IFN-alphaA by CD73: implications for mucosal inflammation. J Immunol. 2008;180:4246-4255.

136. Haskó G, Csóka B, Koscsó B, et al. Ecto-5'-nucleotidase (CD73) decreases mortality and organ injury in sepsis. I Immunol. 2011;187:4256-4267.

137. Hart ML, Jacobi B, Schittenhelm J, Henn M, Eltzschig HK. Cutting Edge: A2B adenosine receptor signaling provides potent protection during intestinal ischemia/reperfusion injury. J Immunol. 2009;182:3965-3968.

138. Clambey ET, McNamee EN, Westrich JA, et al. Hypoxiainducible factor- 1 alpha-dependent induction of FoxP3 drives regulatory T-cell abundance and function during inflammatory hypoxia of the mucosa. Proc Natl Acad Sci U S A. 2012;109:E2784-E2793.

139. Deaglio S, Dwyer KM, Gao W, et al. Adenosine generation catalyzed by CD39 and CD73 expressed on regulatory T cells mediates immune suppression. I Exp Med. 2007;204:1257-1265.

140. Ehrentraut H, Clambey ET, McNamee EN, et al. CD73+ regulatory $\mathrm{T}$ cells contribute to adenosine-mediated resolution of acute lung injury. FASEB J. 2013;27:2207-2219.

141. Ehrentraut H, Westrich JA, Eltzschig HK, Clambey ET. Adora $2 b$ adenosine receptor engagement enhances regulatory $\mathrm{T}$ cell abundance during endotoxin-induced pulmonary inflammation. PLoS One. 2012;7:e32416.

142. Aherne CM, Saeedi B, Collins CB, et al. Erratum: Epithelialspecific $\mathrm{A} 2 \mathrm{~B}$ adenosine receptor signaling protects the colonic epithelial barrier during acute colitis. Mucosal Immunol. 2015;8:699.

143. Gupta R, Chaudhary AR, Shah BN, et al. Therapeutic treatment with a novel hypoxia-inducible factor hydroxylase inhibitor (TRC160334) ameliorates murine colitis. Clin Exp Gastroenterol. 2014;7:13-23.

144. Keely S, Campbell EL, Baird AW, et al. Contribution of epithelial innate immunity to systemic protection afforded by prolyl hydroxylase inhibition in murine colitis. Mucosal Immunol. 2014;7:114-123.

145. Aherne CM, Saeedi B, Collins CB, et al. Epithelial-specific $\mathrm{A} 2 \mathrm{~B}$ adenosine receptor signaling protects the colonic epithelial barrier during acute colitis. Mucosal Immunol. 2015;8:1324-1338. 
146. Pergola PE, Spinowitz BS, Hartman CS, Maroni BJ, Haase VH. Vadadustat, a novel oral HIF stabilizer, provides effective anemia treatment in nondialysis-dependent chronic kidney disease. Kidney Int. 2016;90:1115-1122.

147. Besarab A, Provenzano R, Hertel J, et al. Randomized placebo-controlled dose-ranging and pharmacodynamics study of roxadustat (FG-4592) to treat anemia in nondialysis-dependent chronic kidney disease (NDD-CKD) patients. Nephrol Dial Transplant. 2015;30:1665-1673.

148. Xue X, Taylor M, Anderson E, et al. Hypoxia-inducible factor$2 \alpha$ activation promotes colorectal cancer progression by dysregulating iron homeostasis. Cancer Res. 2012;72:2285-2293.
149. Higgins DF, Kimura K, Bernhardt WM, et al. Hypoxia promotes fibrogenesis in vivo via HIF-1 stimulation of epithelial-to-mesenchymal transition. J Clin Invest. 2007;117:3810-3820.

150. Provenzano R, Besarab A, Sun CH, et al. Oral hypoxia-inducible factor prolyl hydroxylase inhibitor roxadustat (FG-4592) for the treatment of anemia in patients with CKD. Clin J Am Soc Nephrol. 2016;11:982-991.

151. Akizawa T, Tsubakihara Y, Nangaku M, et al. Effects of daprodustat, a novel hypoxia-inducible factor prolyl hydroxylase inhibitor on anemia management in Japanese hemodialysis subjects. Am J Nephrol. 2017;45:127-135. 